\title{
Inhibition of Tumor Angiogenesis Using a Soluble Receptor Establishes a Role for Tie2 in Pathologic Vascular Growth
}

\author{
Pengnian Lin, ${ }^{\star}$ Peter Polverini, ${ }^{\|}$Mark Dewhirst, ${ }^{\ddagger}$ Siqing Shan,, Prema S. Rao, ${ }^{\star}$ and Kevin Peters ${ }^{\star \S}$ \\ $*$ Department of Medicine, ${ }^{\ddagger}$ Department of Radiation Oncology, and ${ }^{\S}$ Department of Pharmacology, Duke University Medical Center, \\ Durham, North Carolina 27710; and ${ }^{\|}$Department of Oral Medicine/Pathology/Surgery, University of Michigan School of Medicine, \\ Ann Arbor, Michigan 48109
}

\begin{abstract}
Tie2 is a novel receptor tyrosine kinase that is expressed almost exclusively by vascular endothelium. Disruption of Tie2 function in transgenic mice resulted in embryonic lethality secondary to characteristic vascular defects; similar defects occurred after disruption of the Tie 2 ligand. These findings indicate that the Tie2/Tie2 ligand pathway plays important roles during development of the embryonic vasculature. To determine whether the Tie 2 pathway was involved in pathologic angiogenesis in adult tissues, a soluble form of the extracellular domain of murine Tie2 (ExTek.6His) was developed and used as a Tie2 inhibitor. After a single application of the ExTek.6His protein into a rat cutaneous window chamber, growth of a mammary tumor inside the chamber was reduced by $>75 \%(P<0.005)$, and tumor vascular length density was reduced by $40 \%$ when compared with control-treated tumors $(P<0.01)$. In the rat cornea, ExTek.6His blocked angiogenesis stimulated by tumor cell conditioned media. ExTek.6His protein did not affect the viability of cultured tumor cells, indicating that the antitumor effect of ExTek.6His was due to the inhibition of tumor angiogenesis. These data demonstrate a role for the Tie2 pathway in pathologic angiogenesis, suggesting that targeting this pathway may yield effective antiangiogenic agents for treatment of cancer and other angiogenic diseases. $(J$. Clin. Invest. 1997. 100:2072-2078.) Key words: endothelium • receptor tyrosine kinase $\bullet$ angiogenesis $\bullet$ Tie 2 • cancer
\end{abstract}

\section{Introduction}

Angiogenesis, the formation of new capillaries from preexisting blood vessels, is a fundamental process required for normal embryonic development and for the development of pathologic conditions such as cancer $(1,2)$. Tumor growth is an angiogenesis-dependent process that requires stimulation of new vessel growth $(3,4)$. For example, in the absence of neovascularization, solid tumors will not grow beyond a few cubic millimeters (2). Moreover, recent studies indicate that tumors with a luxuriant vasculature have a higher fraction of dividing cells

Address correspondence to Kevin G. Peters, M.D., Assistant Professor of Medicine and Pharmacology, Duke University Medical Center, Box 3623, Durham, NC 27710. Phone: 919-684-2119; FAX: 919-6848591; E-mail: kgp@hodgkin.mc.duke.edu

Received for publication 13 March 1997 and accepted in revised form 14 August 1997.

J. Clin. Invest.

(C) The American Society for Clinical Investigation, Inc. 0021-9738/97/10/2072/07 \$2.00

Volume 100, Number 8, October 1997, 2072-2078

http://www.jci.org and lower necrosis rates than do tumors with a poorly developed vasculature $(1,5)$. Recent clinical studies have shown a direct correlation between the density of tumor vessels and an adverse prognosis in patients with a variety of solid tumors including breast, colon, lung, kidney, bladder, and head and neck tumors (6-14). Considering the importance of vascular growth in tumorigenesis, it seems certain that targeting the tumor endothelium will provide effective cancer therapy.

Tumor angiogenesis is most likely mediated by growth factors produced by tumor cells and/or by tumor-infiltrating inflammatory cells such as macrophages or mast cells $(2,15)$. These factors stimulate the proliferation, migration, and morphogenesis of endothelial cells as a result of interaction with specific cell surface receptors. Although many factors likely contribute to vascular growth in tumors, vascular endothelial growth factor (VEGF) ${ }^{1}$ is currently the best candidate for an endogenous mediator of vascular growth $(16,17)$. A role for VEGF and VEGF receptors in tumor angiogenesis is supported by a growing number of reports demonstrating expression of VEGF and VEGF receptors in a number of different tumor types (18-21). Furthermore, blocking the VEGF/VEGF receptor pathway inhibits the growth of a number of murine tumors and human tumor xenographs (22-24). Interestingly, however, a recent study has demonstrated that although many tumors are inhibited by blockade of the VEGF/VEGF receptor pathway, others are unaffected, suggesting that alternative pathways for vascular growth can drive tumor angiogenesis (23).

Recently, a novel endothelium-specific receptor tyrosine kinase Tie2 (a.k.a. Tek) was identified $(25,26)$. Tie2 was expressed predominantly in endothelial cell precursors (angioblasts) and in endothelial cells participating in angiogenesis (27, 28). Disruption of Tie2 function in transgenic mice resulted in embryonic lethality at day 8.5 because of defects in vascular development characterized by a reduction in endothelial cell number and a defect in microvessel formation (29, 30). Similar vascular defects occurred after the disruption of a recently cloned Tie 2 ligand $(31,32)$. These findings indicated that the Tie 2 pathway was essential for formation of the embryonic vasculature, and suggested a role for Tie 2 in pathologic angiogenesis, including tumor neovascularization. In this report, a soluble Tie 2 inhibitor consisting of the entire extracellular portion of murine Tie2 fused to a 6-histidine tag (ExTek.6His) was developed to study the role of the Tie 2 pathway in tumor angiogenesis.

\section{Methods}

Cell lines and antibodies. Recombinant baculovirus was generated and propagated in monolayer-cultured SF9 cells maintained in

1. Abbreviations used in this paper: $\mathrm{DAB}$, diaminobenzidine, $\mathrm{RT}$, reverse transcription; VEGF, vascular endothelial growth factor. 
Grace's Insect Medium Supplemented (GIBCO BRL, Gaithersburg, $\mathrm{MD})$ at $28^{\circ} \mathrm{C}$. Protein expression was carried out in suspension-cultured SF9 cells in Protein-free Insect Medium (PharMingen, San Diego, CA). The R3230AC rat adenocarcinoma cell line was maintained in DMEM plus $10 \%$ FBS (GIBCO BRL) at $37^{\circ} \mathrm{C}$ with $5 \%$ $\mathrm{CO}_{2}$. A mouse monoclonal antibody against the extracellular domain of human Tie2, which specifically recognized the Tie 2 of several species such as mouse, rat, and human, was generated in this lab. The rat endothelial marker MRC-OX43 and biotinylated antimouse immunoglobulin were purchased from Harlan Bioproducts for Science, Inc. (Indianapolis, IN) and DAKO Corp. (Carpinteria, CA), respectively. Horseradish peroxidase-conjugated Streptavidin and diaminobenzidine substrate kits were from BioGenex Labs (San Ramon, CA). Avidin/Biotin blocking and DAB enhancing solution were from Vector Laboratories, Inc. (Burlingame, CA).

Construction of the ExTek.6His baculovirus vector and production of recombinant virus. Using two mouse Tek-specific cDNA primers (5' GGATCCATGGACCTGATC 3', [a Bam HI site was introduced in front of the start codon]; and $3^{\prime}$ CGTCTGGAGCCTAGCTA 5', a Cla I site was introduced at $5^{\prime}$ end), the cDNA from nucleotides $124-2,346$ or amino acids 1-741 of mouse Tie2 (the entire extracellular domain except minus 3 amino acids at the $\mathrm{COOH}$ terminus) was amplified by reverse transcription (RT)-PCR from 9-12-d mouse embryos as previously described (25). The resulting RT-PCR product was digested with $\mathrm{Bam} \mathrm{HI} / \mathrm{Cla}$ I and ligated to the same sites of the BSK Cla-/6His vector (BSK/ExTek.6His). BSK Cla-/6His is a modified BSK vector (Stratagene, La Jolla, CA). The original Cla I site was deleted, and a new Cla I site with an in-frame 6-histidine tag followed by a stop codon was inserted into the Bam HI and Xba I site. A 2.1-kb Eco RI/Not I fragment from BSK/ExTek.6His containing the mouse extracellular domain coding region followed by a sixhistidine tag was subcloned into the same sites of pVL 1393, a baculoviral expression vector (PharMingen). The ExTek.6His transfer plasmid and Baculogold baculoviral DNA (PharMingen) were cotransfected into SF9 cells for production of the recombinant baculovirus BvExTek.6His according to the manufacturer's instructions. Second-passage virus was used to infect serum-free SF9 cells for ExTek.6His protein expression. The same approach was used to generate a recombinant baculovirus (BvExFms.6His) expressing the entire extracellular domain of human c-fms receptor fused to a 6-histidine tag at the $\mathrm{COOH}$ terminus.

Purification of ExTek.6His protein. Spinner-cultured SF9 serumfree insect cells ( 1 liter) were infected with $\sim 1 \mathrm{pfu} / \mathrm{cell}$ of second passage BvExTek.6His for $54 \mathrm{~h}$ at $28^{\circ} \mathrm{C}$. Cells were removed by centrifugation at $3,000 \mathrm{rpm}$ for $20 \mathrm{~min}$ at $4^{\circ} \mathrm{C}$. The supernatant was dialyzed against 8 liters of PBS, $\mathrm{pH} 8.0$ for $48 \mathrm{~h}$ with one change of buffer. The dialyzed supernatant was then incubated with $4 \mathrm{ml}$ of $\mathrm{Ni}^{++} \mathrm{NTA}$ resin (QIAGEN Inc., Chatsworth, CA). After $1 \mathrm{~h}$ at room temperature, the resin-bound ExTek.6His protein was loaded onto a 10-ml column. The column was then washed with $200 \mathrm{ml}$ of wash buffer $(50 \mathrm{mM}$ $\mathrm{NaH}_{2} \mathrm{PO}_{4}, 300 \mathrm{mM} \mathrm{NaCl}$, and $20 \mathrm{mM}$ Imidazole, $\mathrm{pH} 8.0$ ), and the protein was eluted with elution buffer (same as wash buffer except containing $250 \mathrm{mM}$ Imidazole) followed by a buffer change to PBS pH 7.2 by ultrafiltration (Centricon 10; Amicon Inc., Beverly, MA). Control ExFms.6His was purified from SF-9 supernatant infected with BvExFms.6His virus, and followed the same purification protocol. Mock control solution was generated from the supernatant of uninfected SF9 cells following the same purification procedure as for ExTek.6His protein. Aliquots of purified ExTek.6His and ExFms.6His protein and mock control solution were analyzed by SDS-PAGE on a $7.5 \%$ gel.

Tumor window chamber model. Tumors were grown in cutaneous window chambers in Fischer 344 rats (age 12-14 wk, wt 140-160 g; Charles River Labs, Wilmington, MA) as previously described (33). In brief, two 1-cm diameter holes were dissected in opposing epithelial surfaces of the dorsal skin flap as it was retracted away from the posterior surface of the back. The underlying fascia was dissected away until two facial planes with associated vasculature remained. $100 \mu \mathrm{l}$ of ExTek protein $(0.5 \mu \mathrm{g} / \mu \mathrm{l})$ or $100 \mu \mathrm{l}$ of mock control solu- tion was injected between the facial planes. A $0.1 \mathrm{~mm}^{3}$ piece of R3230AC tumor from a donor rat was then placed onto the facial plane, an additional $100 \mu \mathrm{l}$ of ExTek.6His protein or control solution was added, and the chambers were sealed with glass coverslips. The tissue within the chamber is $\sim 200$ microns thick, and is semitransparent. A pair of tumor window chambers were done at each time, one treated with ExTek.6His and the other with mock control solution. The tumor implants in each pair were tailored in similar size from the same larger piece of grossly viable tumor tissue. The areas of tumor implants were measured using an image analysis software (JAVA; Jandel Scientific, San Rafael, CA). The baseline host vasculature, the blood flow, and the proximity of tumor tissue to vessels were scored. Tumor growth and neovascularization was photographed using a dissecting microscope (Stemi SV6; Carl Zeiss, Inc., Thornwood, NY) on days 5,7 , and 10 , and window chambers were harvested for $\mathrm{H} \& \mathrm{E}$ staining on day 10. For immunohistochemistry, a window chamber bearing a 5-d-old untreated $\mathrm{R} 3230 \mathrm{AC}$ tumor was freshly frozen in optimal cutting temperature compound (OCT).

Measurement of tumor volume and tumor vascular length density. To obtain the tumor size, H\&E-stained sections representing the largest cross-sectional area of each tumor were photographed, and the thickness (t) and the diameter (d) of tumors were measured from the photographs. Tumor volumes, which were assumed to approximate a flat cylinder, were calculated using the formula:

tumor volume $\left(\mathrm{mm}^{3}\right)=3.14 \mathrm{t}(\mathrm{d} / 2)^{2}$.

Tumor vascular length density as an indicator of tumor vasculature was measured from photographs of 10-d-old tumors within the window chamber using a previously described method (34). Three to five areas inside the tumor were randomly selected for measurement. The vascular length density in $\mathrm{mm} / \mathrm{mm}^{3}$ was calculated using the formula:

length density $=\mathrm{N} /(4 \mathrm{gdt})$

where $\mathrm{N}$ is the average number of intersections between vessels and grid per sheet; g is number of blocks in grid (54); d is length of one grid square calibrated by a micrometer image at the same magnification $(0.1333 \mathrm{~mm})$; and $\mathrm{t}$ is measured depth of field through which microvessels could be discerned $(0.2 \mathrm{~mm})$.

Rat corneal micropocket assay. In vivo angiogenic activity of ExTek.6His was tested in the avascular cornea of F344 female rat (Harlan Teklad, Madison, WI) as described (33) In brief, each sample was combined with sterile Hydron casting solution (Interferon Sciences, New Brunswick, NJ), and the solution was pipetted onto the surface of 1.5-mm diameter Teflon rods (DuPont-Merck Pharmaceutical Co., Wilmington, DE). The pellets were air-dried in a laminar hood for $1 \mathrm{~h}$ and refrigerated overnight. The following day, pellets were rehydrated with a drop of PBS buffer, and were then placed in a surgically created pocket within the cornea stroma, $1.5 \mathrm{~mm}$ from the limbus. Corneas were observed every other day until day 5 or 7 when the animals were anesthetized and perfused with lactated ringers solution followed by colloid carbon solution to enumerate the vessels. Responses were scored as positive when vigorous and sustained directional ingrowth of capillary sprouts and hairpin loops toward the implant were detected. Negative responses were recorded when no growth was detected, or when there was only an occasional sprout or hairpin loop with no evidence of sustained growth. Positive controls consisted of Hydron pellets containing $25 \mathrm{ng} / 5 \mu \mathrm{l}$ pellet. Negative controls consisted of sham implants and Hydron pellets containing media alone. Media was incorporated into pellets at a concentration of $1 \mu \mathrm{g}$ of total protein per cornea. Representative corneas were examined histologically, and except for occasional neutrophils found in the limbus of both control and test corneas, nonspecific inflammation was not a contributing factor in any of the corneal responses (data not shown).

In vitro cell proliferation. $\mathrm{R} 3230 \mathrm{AC}$ tumor cells were seeded at $4 \times$ $10^{4} /$ well into 12 -well plates, and were maintained in the presence of purified ExTek.6His protein $(3 \mu \mathrm{M})$ or control solution. Cell mor- 
phology was monitored every day by light microscope. Live cells were trypsinized, suspended in PBS containing 0.02\% Trypan blue (GIBCO BRL), and were counted with a hemocytometer each following day for $3 \mathrm{~d}$.

Histochemistry and anti-Tie2 immunohistochemistry. Tumor windows to be processed for H\&E staining were fixed in $4 \%$ paraformaldehyde overnight at $4^{\circ} \mathrm{C}$ and embedded in paraffin. Samples for immunohistochemistry were freshly frozen in liquid nitrogen and embedded in OCT. For immunohistochemistry, serial sections of 10 microns were cut, fixed in ice-cold acetone for $10 \mathrm{~min}$, and blocked with $0.03 \% \mathrm{H}_{2} \mathrm{O}_{2}, 1 \%$ horse serum, and avidin/biotin blocking reagents (Vector Laboratories). After blocking, sections were incubated with a monoclonal anti-Tie2 antibody or an antibody specific for rat endothelium (MRC-OX43) in a humidified chamber for 50 min at room temperature. With PBS washes between all steps, a biotinylated linker antibody (DAKO Corp.) was applied for $30 \mathrm{~min}$, followed by another 30-min incubation with streptavidin-linked HRP. Peroxidate activity was localized with diaminobenzidine (DAB) and was enhanced by DAB-enhancing solution (Vector Laboratories). Sections were then weakly counterstained with hematoxylin.

Statistics. Results are reported as mean \pm SE for tumor volume and tumor vascular length density for each group. A two-tailed Student's $t$ test was used to analyze statistical differences between the control-treated group and the ExTek-treated group. Differences were considered statistically significant at $p<0.05$.

\section{Results}

Design and production of ExTek.6His fusion protein. We reasoned that a recombinant soluble extracellular domain of Tie2 (ExTek) should compete with the endogenous receptor for ligand binding, thus inhibiting receptor activation. To produce large amounts of properly processed ExTek protein and a control protein, ExFms (extracellular domain of the CSF-1 receptor), recombinant baculovirus vectors directing expression of ExTek or ExFms protein fused to a 6-histidine tag, were constructed (Fig. $1 A$ ). ExTek.6His and ExFms.6His were purified from the supernatant of baculovirus-infected SF9 cells by onestep $\mathrm{Ni}^{++} \mathrm{NTA}$ resin chromatography, yielding a single major
Table I. Inhibitory Effect of ExTek.6His on Angiogenic Response Induced by Tumor Conditioned Media

\begin{tabular}{llc}
\hline & \multicolumn{2}{c}{ Proportion of corneal angiogenic responses (\%) } \\
\cline { 2 - 3 } \multicolumn{1}{c}{ Samples } & \multicolumn{1}{c}{ Negative } & Strong positive \\
\hline Fresh media & $3 / 3(100 \%) *$ & \\
ExTek.6His & $2 / 2(100 \%)$ & \\
ExFms.6His & $4 / 4(100 \%)$ & $3 / 3(100 \%)$ \\
Conditioned medium & & \\
CM + ExTek.6His & $4 / 4(100 \%)$ & $3 / 3(100 \%)$ \\
CM + ExFms.6His & &
\end{tabular}

$* \mathrm{n} / \mathrm{m}(\mathrm{x}): \mathrm{m}$ is the number of rats used in each experiment; $\mathrm{n}$ is the number of rats with the indicated response; $x$ is the percentage of rats with the indicated response. CM, conditioned medium.

band of the expected molecular mass for each protein (Fig. 1 $B$, lanes 2 and 3, respectively). The identity of the ExTek protein was further confirmed by Western blot by using a monoclonal anti-Tie2 antibody (data not shown). A mock control solution was purified from uninfected SF9 cell supernant using the same protocol (Fig. $1 B$, lane 4 ).

ExTek.6His blocks angiogenesis stimulated by tumor cell conditioned media. First, the ability of ExTek.6His to block angiogenesis in rat corneas was tested (35). Hydron pellets containing fresh media $(5 \mu \mathrm{l})$, ExTek.6His (100 ng), or ExFms.6His (100 ng) alone failed to stimluate an angiogenic response in rat cornea 5-7 d after implantation (Table I). A strong angiogenic response was seen, however, with pellets containing R3230AC tumor cell-conditioned media ( $1 \mu \mathrm{g}$ total protein). This angiogenic response was completely blocked by addition of $100 \mathrm{ng}$ of ExTek.6His into the pellets containing tumor cell-conditioned media. Addition of control protein ExFms.6His (100 ng) to pellets containing tumor cell-condi-

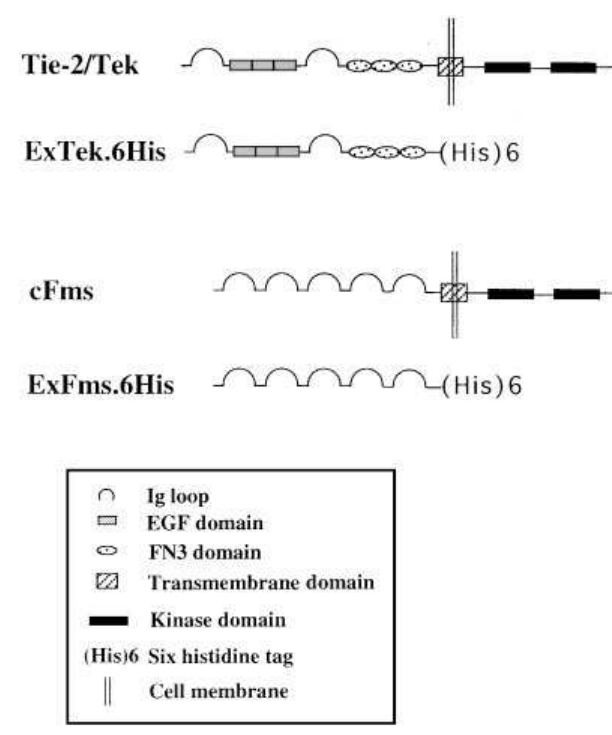

A
Figure 1. Design and production of ExTek.6His. Schematic diagrams of the fulllength Tie2 and CSF-1 receptors, c-Fms, together with their respective soluble extracellular domains fused at the carboxy terminus to a 6 histidine tag (ExTek.6His and ExFms.6His) (A). Recombinant baculoviruses were constructed for production of soluble recombinant ExTek.6His and ExFms.6His by insect cells. ExTek.6His and ExFms.6His were purified from the conditioned media of baculovirus-infected $\mathrm{sF} 9$ cells by one-step $\mathrm{Ni}^{++} \mathrm{NTA}$ agarose chromatography, and were analyzed by $7.5 \%$ SDS-PAGE followed by Coomassie staining $(B)$. The expected 90-kD ExTek.6His protein (lane 2) and 72-kD ExFms.6His protein (lane 3 ) were purified to near homogeneity by this simple procedure. Lanes were loaded as follows: lane 1, molecular mass markers; lane 2, $0.5 \mu \mathrm{g}$ of purified ExTek.6His protein; lane 3, $1 \mu \mathrm{g}$ of purified ExFms.6His; lane 4 , an equal volume of mock control solution purified from the supernatant of uninfected sF9 cells. 

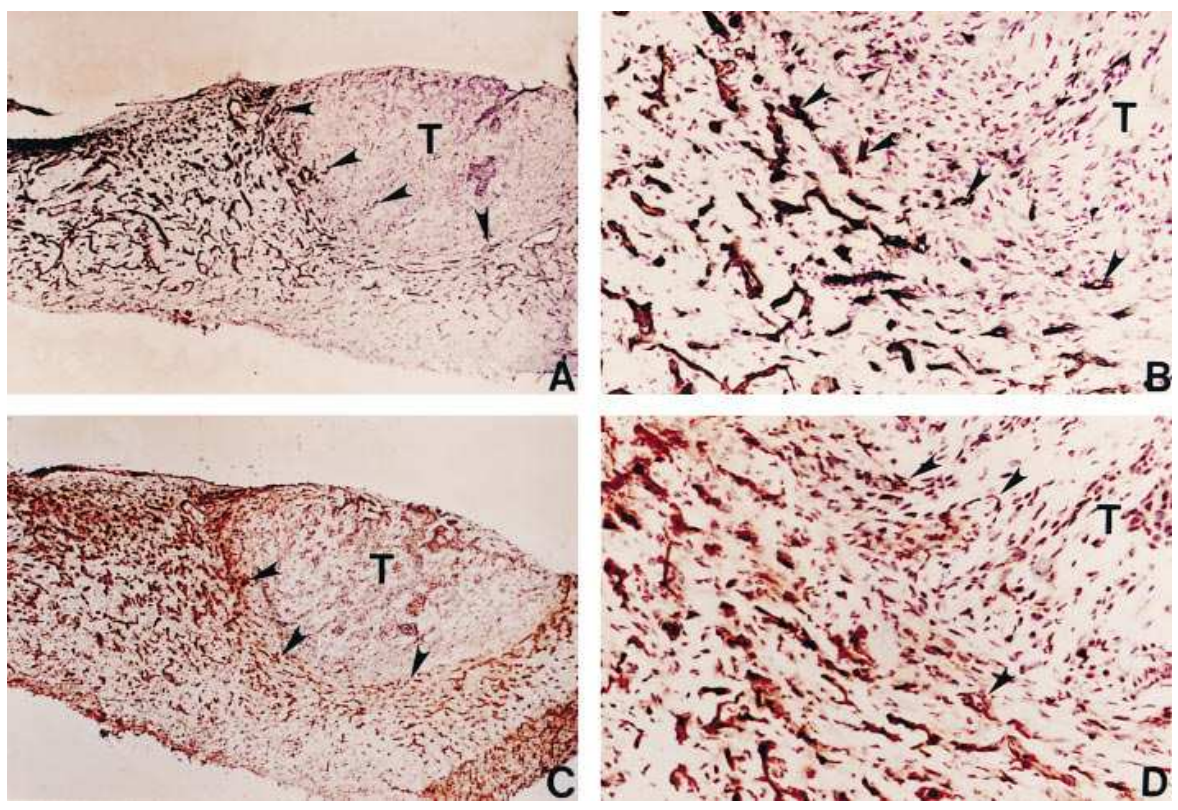

Figure 2. Expression of the Tie2 receptor tyrosine kinase in the endothelium of vessels surrounding and penetrating a rat mammary carcinoma grown in a cutaneous window chamber. Frozen sections of a 5-d-old R3230AC tumor tissue in a rat window chamber were analyzed by immunohistochemistry using antibodies against the extracellular domain of Tie2 $(A$ and $B)$ and a specific endothelial marker (MRC-OX43; $C$ and $D$ ). Strong Tie2 staining was observed in vessels surrounding and penetrating the 5-d-old tumor as well as in the healing vasculature of the wounded subcutaneous tissue ( $A$ and $B$ ). A similar pattern of staining was seen for the endothelial marker demonstrating that Tie 2 was expressed specifically by endothelial cells $(C$ and $D$ ). Arrowheads indicate the newly formed vessels penetrating the edge of the tumor. $A$ and $C, 40 \times ; B$ and $D, 200 \times$. tioned media did not block the angiogenic response. These results demonstrated that ExTek.6His specifically and potently inhibited corneal angiogenesis induced by tumor-conditioned media in vivo, and suggested its potential application as an antiangiogenic agent for cancer therapy.

Tie2 is expressed in tumor vessels at the onset of tumor angiogenesis. To address the possible role of Tie2 in tumor angiogenesis and tumor growth, purified ExTek.6His protein was used as an inhibitor in a rat cutaneous window chamber bearing a R3230AC mammary tumor. Previous work has demonstrated that small fragments of tumor $\left(0.1 \mathrm{~mm}^{3}\right)$ placed in a window chamber become vascularized, and undergo rapid growth within 10-14 d (34). Typically, vascularization of tumors in the window chamber is first detected at $\sim 5 \mathrm{~d}$ after im- plantation, and is followed by a rapid growth phase of the tumor. Consistent with a role for Tie 2 in vascularization of the R3230AC mammary tumor, immunohistochemical studies demonstrated expression of Tie2 in vessels surrounding and penetrating the tumor implant $5 \mathrm{~d}$ after implantation (Fig. 2).

ExTek inhibits tumor growth in cutaneous window chambers. To determine the functional significance of Tie 2 expression during tumor angiogenesis, a single dose of purified ExTek.6His protein $(100 \mu \mathrm{g})$ was administered directly into the window chamber at the time of tumor implantation. After $10 \mathrm{~d}$, gross inspection of live tumors in the tumor window and examination of histologic sections, demonstrated that tumors $(n=9$ pairs) treated with ExTek.6His protein were smaller, contained more connective tissue, and had a less well-developed
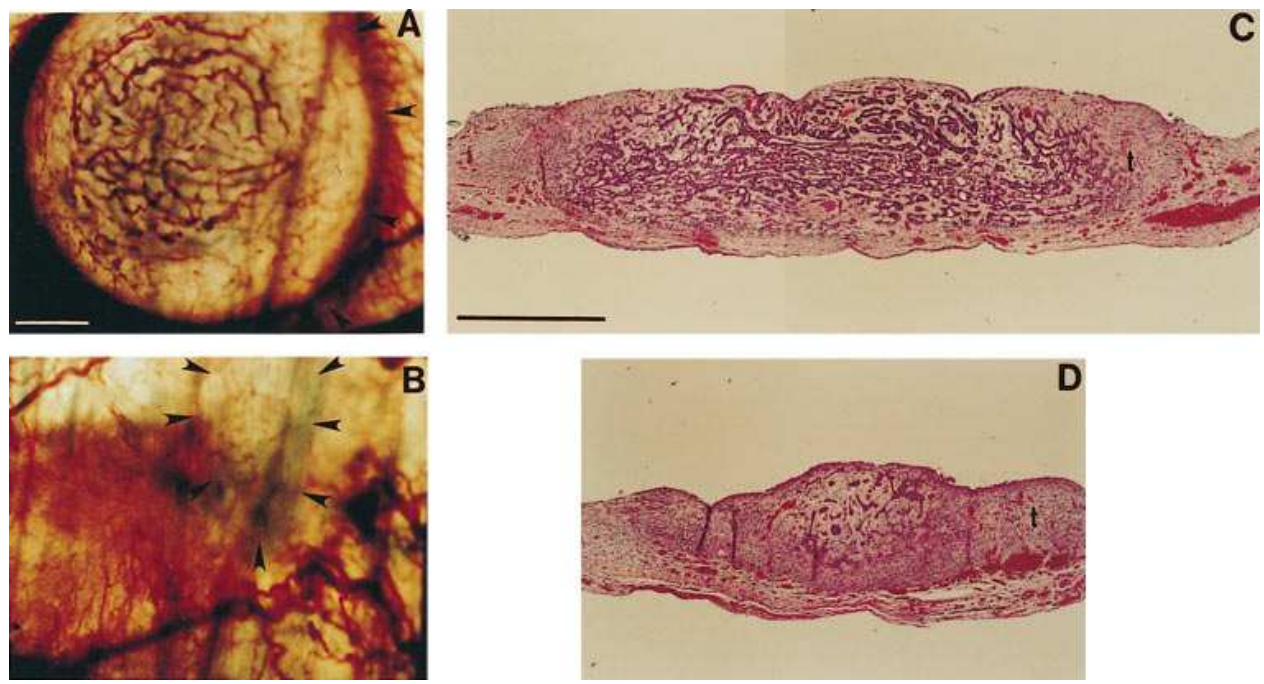

C Figure 3. Inhibition of tumor growth and tumor vascularization in a cutaneous window chamber after a single administration of ExTek.6His protein. To determine the effect of ExTek.6His on tumor growth, $200 \mu$ l of purified

ExTek.6His protein $(0.5 \mu \mathrm{g} / \mu \mathrm{l})$ or an equal volume of control solution was administered directly into window chambers at the time of tumor implantation. After $10 \mathrm{~d}$, the mock control-treated and the ExTek.6His-treated tumors were photographed within the window chamber $(A$ and $B)$. The animals were then killed and the tissue within the tumor windows was removed for histologic examination $(C$ and $D)$. Untreated tumors grew rapidly and developed a luxuriant

intratumor vasculature and an obvious peritumor-hypervasculature border zone $(A$ and $C)$. In contrast, ExTek.6His-treated tumors were consistently much smaller than control treated tumors, and possessed a sparse vasculature with no obvious hypervascular border zone $(B$ and $D)$. Arrowheads indicate the tumor margins $(A$ and $B)$. $A$ and $B, 20 \times ; C$ and $D, 40 \times$. Bar represents $1 \mathrm{~mm}$. 


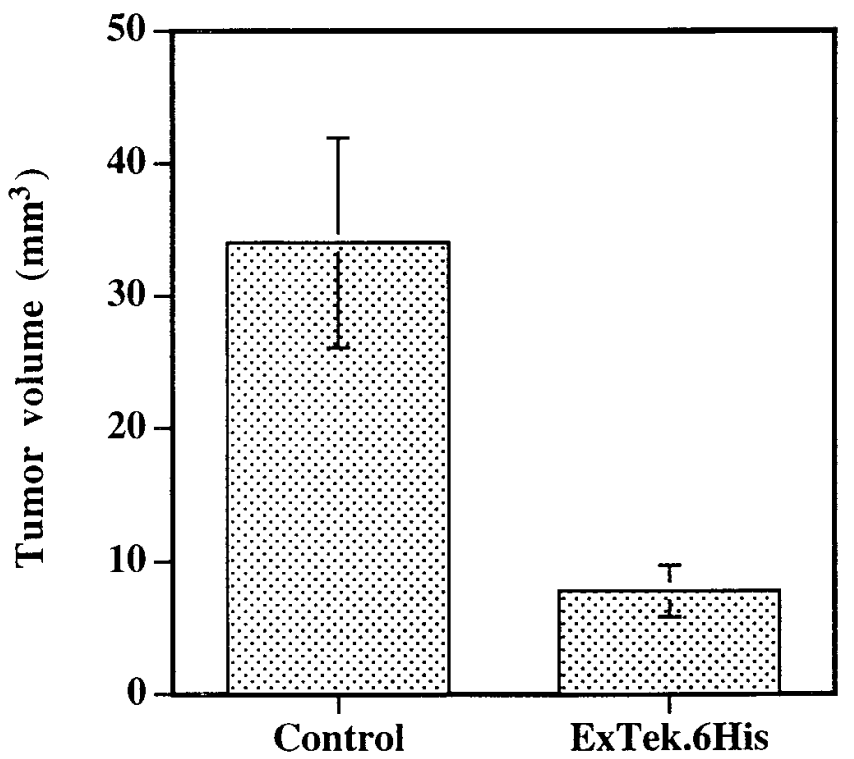

Figure 4. Inhibition of tumor growth in a cutaneous window chamber after a single administration of ExTek.6His protein. To determine whether inhibiting the Tie2 pathway for tumor angiogenesis could inhibit tumor growth, $200 \mu \mathrm{l}$ of purified ExTek.6His protein $(0.5 \mu \mathrm{g} / \mu \mathrm{l})$ or an equal volume of control solution was placed directly in the window chamber at the time of tumor implantation. $10 \mathrm{~d}$ later, the animals were killed, and window chambers were removed for histochemical analysis. To compare the size of the ExTek.6His-treated tumors vs. the control-treated tumors, the tumor volume was calculated from the largest H\&E-stained tumor cross-section. Using this index, a $>75 \%$ reduction in tumor growth was observed in ExTek.6Histreated tumors vs. control-treated tumors $(n=9$ pairs, $P<0.005)$. Error bars indicate SE.

vasculature with no clear hypervascular boundary when compared with tumors in the control group (Fig. 3). Comparing tumor size by estimating tumor volume confirmed that the ExTek.6His-treated tumors were on average $\sim 75 \%$ smaller than the mock control-treated tumors (Fig. 4). No inhibition of tumor growth was observed when ExFms.6His was used. An alternative form of ExTek possessing a strep-tag gave similar growth inhibition (data not shown).

ExTek.6His inhibits tumor vascularization. The above results suggested that inhibition of tumor angiogenesis by ExTek limited tumor growth. To support this notion, tumor vascular length density was measured from photomicrographs of tumor window chambers bearing ExTek.6His-treated or mock control-treated tumors $10 \mathrm{~d}$ after implantation. Consistent with inhibition of tumor angiogenesis, there was an $\sim 40 \%$ reduction in tumor vessel length density in ExTek.6His treated tumors vs. mock control-treated tumors $(n=9$ pairs, $P<0.01$; Fig. 5). Considering the documented strong link between tumor growth and tumor angiogenesis, the ability to measure any decrement in tumor vascular density strongly suggests that the primary action of the ExTek.6His protein was to inhibit tumor neovascularization.

ExTek.6His does not directly affect tumor cell proliferation or viability. To confirm further that the primary effect of ExTek6His was on the tumor vasculature, the cytotoxicity of the ExTek.6His protein on cultured R3230AC cells was assayed. When cells were cultured in the presence of $3 \mu \mathrm{M}$ of

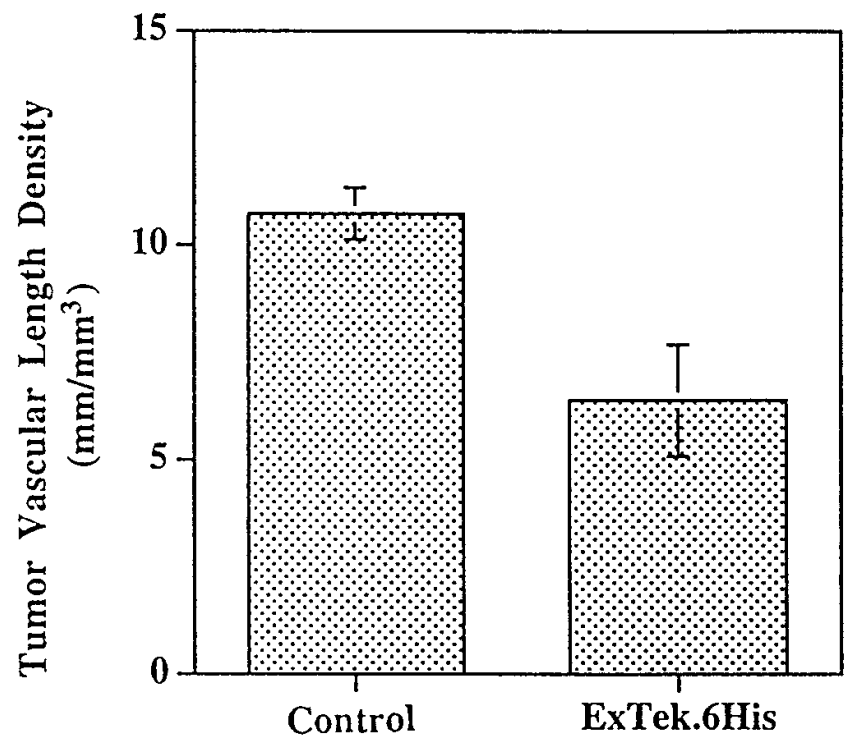

Figure 5. Inhibition of tumor vascularization by ExTek.6His protein. Tumor vessel length density was measured as an indicator of tumor vascularization from photomicrographs of window chambers bearing 10-d-old ExTek.6His-treated tumors or control-treated tumors. A single administration of ExTek.6His protein resulted in an $\sim 40 \%$ reduction in tumor vessel length density $(n=9$ pairs, $P<0.01)$.

ExTek.6His protein, no difference in tumor cell proliferation or viability was observed when compared with control (Fig. 6). This result suggests that inhibition of tumor growth by ExTek in vivo was not mediated by direct tumor toxicity.

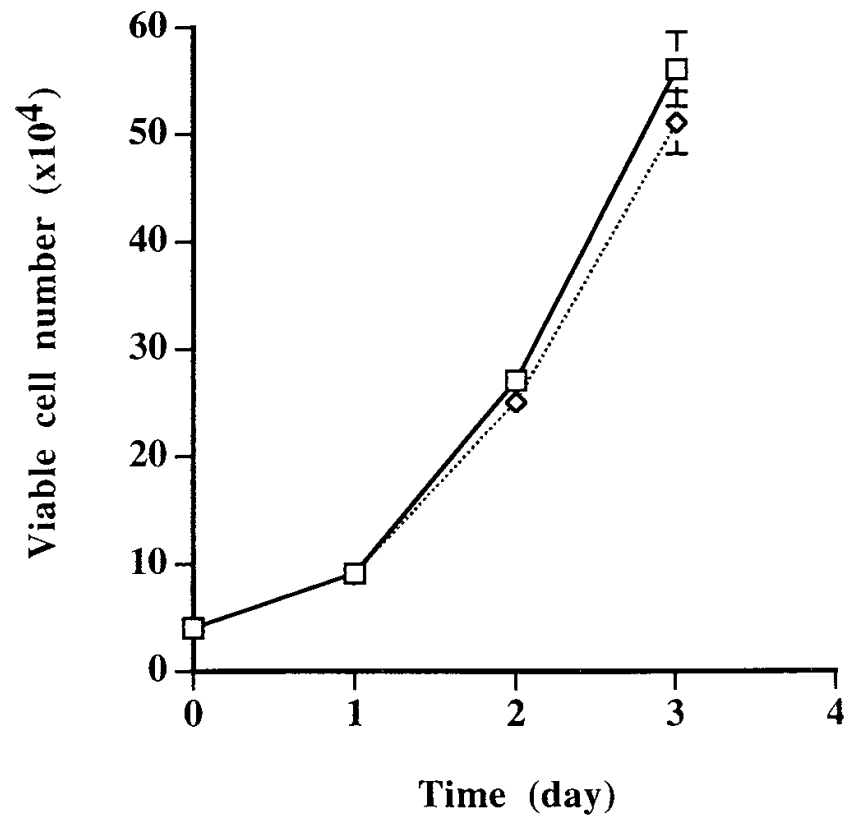

Figure 6. ExTek.6His protein did not adversely effect R3230AC tumor cell proliferation or viability. Cells were either maintained in the presence of ExTek.6His protein at $3 \mu \mathrm{M}$, which was approximately equivalent to the protein concentration used in the window chamber, or control solution for $3 \mathrm{~d}$. Live cells were counted after suspension in PBS with $0.02 \%$ trypan blue on each following day. Each point represents the mean of three experiments. Open squares, control; open diamonds, ExTek.6His. 


\section{Discussion}

Previous studies have demonstrated a role for VEGF receptor tyrosine kinases in tumor angiogenesis (22-24). This study demonstrates that another endothelium-specific receptor tyrosine kinase, Tie2, likely triggers an alternative pathway for tumor neovascularization. A single dose of a recombinant Tie2-soluble extracellular domain resulted in a $75 \%$ reduction in tumor growth over a period of $10 \mathrm{~d}$. The ability of ExTek.6His to block tumor growth was likely secondary to a blockade in tumor angiogenesis. This notion was supported by the decrement in vascular length density in the ExTek.6Histreated tumors, by the ability of ExTek.6His to inhibit corneal angiogenesis stimulated by tumor cell-conditioned media, and by the absence of cytotoxicity of ExTek.6His for cultured tumor cells. These findings are the first demonstration of the Tie2 pathway as a potentially important alternative pathway for tumor angiogenesis, and suggest that therapeutic approaches designed to inhibit the Tie 2 pathway could be clinically useful.

In a window chamber bearing a 5-d-old R3230AC tumor, strong Tie2 expression was observed at the edge of the tumor as well as in neovessels penetrating the substance of the tumor (Fig. 2, $A$ and $B$ ). A similar pattern of Tie2 localization was also observed in human breast tumors, in which the strongest Tie2 expression was localized at the tumor boundary in hot spots of tumor neovascularization (K. Peters, unpublished data). These results are consistent with a role for Tie2 in capillary sprouting from surrounding normal tissues, tumor vessel elongation, and/or formation of connections between tumor vessels and host vessels. The similarity of the expression patterns between human breast tumors and the R3230AC tumor suggests that tumor neovascularization in human tumors may also be driven, at least in part, by the Tie 2 pathway.

Interestingly, ExTek treatment did not appear to affect angiogenesis in surrounding normal tissues undergoing wound healing, in spite of strong Tie 2 expression in the wound vessels. This finding supports the concept that there are several pathways that can cooperatively regulate angiogenesis in adulthood. It is well-documented that tumor vessels have characteristic structural abnormalities when compared with normal vessels (36-39). These structural abnormalities may be the result of unbalanced neovascularization driven by an incomplete complement of signaling pathways, in comparison with balanced neovascularization in physiologic processes such as tumor angiogenesis that are driven by several cooperating pathways. Studies are currently in progress to examine formally the effect of ExTek.6His on wound healing.

A recent study demonstrated that different mouse mammary tumors had disparate responses after blockade of the VEGF pathway (23). Importantly, tumors that did not respond well to blockade of the VEGF pathway expressed Tie2. This finding led these investigators to speculate that the Tie2 pathway might be the major pathway for vascularization of tumors that fail to respond to VEGF inhibition. Our study is the first to demonstrate the potential importance of the Tie 2 pathway as an alternative pathway for tumor angiogenesis. Taken together, these studies suggest that, in a clinical setting, it may be important to determine which angiogenic pathway is most likely being used by an individual tumor to tailor antiangiogenic therapy.

Several lines of evidence suggest that the Tie-2 pathway is required for a later stage in vessel formation than is the VEGF pathway. First, angiopoietin 1, the newly cloned Tie-2 ligand, does not appear to stimulate endothelial proliferation or migration, two VEGF-stimulated responses that are important for the initial phases of vascular growth (32). Moreover, disruption of either Tie- 2 or angiopoietin- 1 in transgenic mice does not apparently effect the earliest steps in the patterning of the vasculature, but rather results in marked abnormalities of microvessel branching and morphogenesis (29-31). Based on these results, it is likely that ExTek.6His blocks tumor angiogenesis at a step distal to endothelial activation. Interestingly, the tumor cell line used in this study produces VEGF, and VEGF was present in the tumor cell-conditioned media used to stimulate angiogenesis in the corneal assay (P. Lin and K. Peters, unpublished data). The ability of ExTek.6His to inhibit angiogenesis despite the presence of VEGF suggests that disrupting the angiogenic program at stages distal to endothelial activation will provide effective and perhaps more globally useful inhibitors of pathologic neovascularization.

This study demonstrates that Tie 2 is an important mediator of tumor angiogenesis. These results suggest that the Tie2 pathway may also be involved in other forms of pathologic angiogenesis such as in retinal neovascularization, arthritis, and atherosclerosis. Thus, it is possible that inhibitors targeting the Tie2 pathway will have broad clinical utility. Current efforts are directed towards testing the role of the Tie2 pathway in other forms of pathologic angiogenesis besides tumor angiogenesis, improving the delivery of ExTek.6His using gene transfer approaches, developing rational inhibitors of the Tie2 pathway using ExTek.6His as an affinity target, and determining the signal transduction pathways downstream of Tie2 as targets for inhibition of specific angiogenic cellular responses.

\section{Acknowledgments}

We thank Drs. Wolfgang Joklik, James Iglehart, Jack Keene, and Charles Greenberg at Duke University Medical Center for their comments on the manuscript.

This work was supported by the National Cancer Institute Special Program of Research Excellence (SPORE) in Breast Cancer at Duke University (CA-66228), by an RO1 from the National Heart, Lung and Blood Institute (HL-54479), and by a scholarship from the James S. McDonnell Foundation.

\section{References}

1. Folkman, J. 1990. What is the evidence that tumors are angiogenesis dependent? J. Natl. Cancer Inst. 82:4-6.

2. Folkman, J., and Y. Shing. 1992. Angiogenesis. J. Biol. Chem. 267:1093110934.

3. Viglietto, G., D. Maglione, M. Rambaldi, J. Cerutti, A. Romano, F. Trapasso, M. Fedele, P. Ippolito, G. Chiapetta, G. Botti, et al. 1995. Upregulation of vascular endothelial growth factor (VEGF) and down regulation of placenta growth factor (PIGF) associated with malignancy in human thyroid tumors and cell lines. Oncogene. 11:1569-1579.

4. Kandel, J., E. Bossy-Wetzel, F. Radvanyi, M. Klagsbrun, J. Folkman, and D. Hanahan. 1991. Neovascularization is associated with a switch to the export of bFGF in the multistep development of fibrosarcoma. Cell. 66:1095-1104.

5. Lyng, H., A. Skretting, and E.K. Rofstad. 1992. Blood flow in six human melanoma xenograft lines with different growth characteristics. Cancer Res. 52: 584-592.

6. Albo, D., M.S. Granick, N. Jhala, B. Atkinson, and M.P. Solomon. 1994 The relationship of angiogenesis to biological activity in human squamous cell carcinomas of the head and neck. Ann. Plast Surg. 32:588-594.

7. Bosari, S., A.K. Lee, R.A. DeLellis, B.D. Wiley, G.J. Heatley, and M.L. Silverman. 1992. Microvessel quantitation and prognosis in invasive breast carcinoma. Hum. Pathol. 23:755-761.

8. Denijn, M., and D.J. Ruiter. 1993. The possible role of angiogenesis in 
the metastatic potential of human melanoma. Clinicopathological aspects. $\mathrm{Mel}$ anoma Res. 3:5-14.

9. Guinebretiere, J.M., G. Le Monique, and J. Bahi. 1994. Angiogenesis and risk of breast cancer in women with fibrocystic disease. J. Natl. Cancer Inst. 86: 635-636.

10. Macchiarini, P., M.J. Hardin, G. Fontanini, F. Squartini, and C.A. Angeletti. 1992. Relation of neovascularization to metastasis of non-small-cell lung cancer. Lancet. 340:145-146.

11. Toi, M., J. Kashitani, and T. Tominaga. 1993. Tumor angiogenesis is an independent prognostic indicator in primary breast carcinoma. Int. J. Cancer. 55:371-374.

12. Weidner. N., P.R. Carroll, J. Flax, W. Blumenfeld, and J. Folkman. 1993. Tumor angiogenesis correlates with metastasis in invasive prostate carcinoma. Am. J. Pathology. 143:401-409.

13. Weidner, N., J. Folkman, F. Pozza, P. Bevilacqua, E.N. Allred, D.H. Moore, S. Meli, and G. Gasparini. 1992. Tumor angiogenesis: a new significant and independent prognostic indicator in early-stage breast carcinoma. J. Natl. Cancer Inst. 84:1875-1887.

14. Weidner, N., J.P. Semple, W.R. Welch, and J. Folkman. 1991. Tumor angiogenesis and metastasis-correlation in invasive breast carcinoma. N. Engl. J. Med. 324:1-8.

15. Sunderkotter, C., K. Steinbrink, M. Goebeler, R. Bhardwaj, and C. Sorg. 1994. Macrophages and angiogenesis. J. Leukocyte Biol. 55:410-422.

16. Connolly, D.T. 1991. Vascular permeability factor: a unique regulator of blood vessel function. J. Cell Biochem. 47:219-223.

17. Ferrara, N., K.A. Houck, L.B. Jakeman, J. Winer, and D.W. Leung. 1991. The vascular endothelial growth factor family of polypeptides. J. Cell Biochem. 47:211-218.

18. Warren, R.S., H. Yuan, M.R. Matli, N.A. Gillett, and N. Ferrara. 1993. Regulation by vascular endothelial growth factor of human colon cancer tumorigenesis in a mouse model of experimental liver metastasis. J. Clin. Invest. 95: 1789-1797.

19. Plate, K.H., G. Breier, B. Millauer, A. Ullrich, and W. Risau. 1993. Upregulation of vascular endothelial growth factor and its cognate receptors in a rat glioma model of tumor angiogenesis. Cancer Res. 53:5822-5827.

20. Plate, K.H., G. Breier, H.A. Weich, and W. Risau. 1992. Vascular endothelial growth factor is a potential tumor angiogenesis factor in human gliomas in vivo. Nature (Lond.). 359:845-848.

21. Hatva, E., A. Kaipainen, P. Mentula, J. Jaaskelainen, A. Paetau, M. Haltia, and K. Alitalo. 1995. Expression of endothelial cell-specific receptor tyrosine kinases and growth factors in human brain tumors. Am. J. Pathol. 146: 368-378.

22. Kim, K.J., B. Li, J. Winer, M. Armanini, N. Gillett, H.S. Phillips, and N. Ferrara. 1993. Inhibition of vascular endothelial growth factor-induced angiogenesis suppresses tumor growth in vivo. Nature (Lond.). 362:841-844.

23. Millauer, B. M.P. Longhi, K.H. Plate, L.K. Shawver, W. Risau, A. Ullrich, and L.M. Strawn. 1996. Dominant-negative inhibition of Flk-1 suppresses the growth of many tumor types in vivo. Cancer Res. 56:1615-1620.

4. Millauer, B., L.K. Shawver, K.H. Plate, W. Risau, and A. Ullrich. 1994. Glioblastoma growth inhibited in vivo by a dominant-negative Flk-1 mutant. Nature (Lond.). 367:576-579.
25. Dumont, D.J., G.J. Gradwohl, G.-H. Fong, R. Auerbach, and M.L. Breitman. 1993. The endothelial-specific receptor tyrosine kinase, tek, is a member of a new subfamily of receptors. Oncogene. 8:1293-1301.

26. Iwama, A., I. Hamaguchi, M. Hashiyama, Y. Murayama, K. Yasungra, and T. Suda. 1993. Molecular cloning and characterization of mouse tie and tek receptor tyrosine kinase genes and their expression in hematopoietic cells. Biochem. Biophys. Res. Commun. 195:301-309.

27. Schnurch, H., and W. Risau. 1993. Expression of Tie2, a member of a novel family of receptor tyrosine kinase, in the endothelial cell lineage. Development. 119:957-968.

28. Dumont, D.J., G.H. Fong, M.C. Puri, G. Gradwohl, K. Alitalo, and M.L. Breitman. 1995. Vascularization of the mouse embryo: a study of flk-1, tek, tie, and vascular endothelial growth factor expression during development. Dev. Dyn. 203:80-92.

29. Sato, T.N., Y. Tozawa, U. Deutsch, K. Wolburg-Buchholz, Y. Fujiwara, M. Gendron-Maguire, T. Gridley, H. Wolburg, W. Risau, and Y. Qin. 1995. Distinct roles of the receptor tyrosine kinase Tie-1 and Tie2 in blood vessel formation. Nature (Lond.). 376:70-74.

30. Dumont, D.J., G. Gradwohl, G.H. Fong, M.C. Puri, M. Gertsenstein, A Averbach, and M.L. Breitman. 1994. Dominant-negative and targeted null mutations in the endothelial receptor tyrosine kinase, tek, reveal a critical role in vasculogenesis of the embryo. Genes and Dev. 8:1897-1909.

31. Suri, C., P.F. Jones, S. Patan, S. Bartunkova, P.C. Maisonpierre, S. Davis, T.N. Sato, and G.D. Yancopoulos. 1996. Requisite role of angiopoietin-1, a ligand for the Tie2 receptor, during embryonic angiogenesis. Cell. 87:11711180

32. Davis, S., T.H. Aldrich, P.F. Jones, A. Acheson, D.L. Compton, V. Jain, T.E. Ryan, J. Bruno, C. Radziejewski, P.C. Maisonpierre, and G.D. Yancopoulos. 1996. Isolation of angiopoietin-1, a ligand for the tie 2 receptor, by secretion-trap expression cloning. Cell. 87:1161-1169.

33. Papenfuss, D., J.F. Gross, M. Intaglitta, and F.A. Treese. 1979. A transparent access chamber for the rat dorsal skin fold. Microvasc. Res. 18:311-318.

34. Dewhirst, M.W., R.Z. Vinuya, E.T. Ong, B. Klitzman, G. Rosner, T.W. Secomb, and J.F. Gross. 1992. Effects of bradykinin on the hemodynamics of tumor and granulating normal tissue microvasculature. Radiat. Res. 130:345354.

35. Polverini, P.J., N.P. Bouck, and F. Rastinejad. 1991. Assay for purification of naturally occurring inhibitors of angiogenesis. Methods Enzymol. 198: $440-450$.

36. Dvorak, H.F., J.A. Nagy, J.T. Dvorak, and A.M. Dvorak. 1988. Identification and characterization of the blood vessels of solid tumors that are leaky to circulating macromolecules. Am. J. Pathol. 133:95-109.

37. Blood, C.H., and B.R. Zetter. 1990. Tumor interactions with the vasculature: angiogenesis and tumor metastasis. Biochim. Biophys. Acta. 1032:89118.

38. Vaupel, P., F. Kallinowski, and P. Okunieff. 1989. Blood flow, oxygen and nutrient supply, and metabolic microenviroment of human tumors: a review. Cancer Res. 49:6449-6465.

39. Jain, R.K. 1988. Determinants of tumor blood flow: a review. Cancer Res. 48:2641-2658. 